\title{
To study the effect of sprouted fenugreek seeds as nutraceutical as an add-on therapy in patients of diabetes mellitus, obesity and metabolic syndrome
}

\begin{abstract}
Fenugreek (methi) is an annual herb mainly cultivated for seed as well as for its sprouts. The sprouts are used as spices and condiment to improve the flavor and the nutritive value of foods. The sprouted fenugreek seeds used as to lower the PPBS, FBS \& metabolic syndrome of the patients. The study was conducted at Maharishi Aurobindo Subharti College \& Hospital of Naturopathy \& Yogic Sciences, Swami Vivekanand Subharti University, Meerut. A total number of 100 patients with metabolic syndrome (diabetic and obese) were selected. They were grouped into two, group one treatment group (50) consumed $25 \mathrm{gm}$ sprouted fenugreek seeds orally twice daily for 45 days and the second group was control (50). In the study from the total 100 individuals, $n=90$ were involved, 40 in treatment group and 50 in the control group. Blood glucose level, weight, BMI, B.P. and Pulse Rate was measured from each participant before and after the study. Data entry and analysis was performed using SPSS version 20 statistical software. Data were presented as mean \pm SD. A level of $p<0.05$ was considered statistically significant. Treatment group had significantly reduced fasting blood glucose and Post-prandial blood sugar level $(\mathrm{P}<0.05)$ compared with the baseline fasting blood glucose level, and the control group. Treatment group had also shows significantly lower $(\mathrm{P}<0.05) \mathrm{BMI}, \mathrm{BP}, \mathrm{PR}$ and weight and compared with their baseline level and control group. However, fasting blood glucose level and Postprandial levels in control group were not significantly changed. The present study shows that administration of sprouted fenugreek seeds had pronounced effects on improving glucose level and metabolic parameters such as weight, BMI, BP and Pulse rate in type II diabetic patients and obese patients with negligible adverse effects.
\end{abstract}

Volume 6 Issue 4 - 2018

\author{
Firoz Khan, Prem Prakash Khosla \\ Department of Pharmacology, Netaji Subhash Chandra Bose \\ Subharti Medical College, India
}

Correspondence: Firoz Khan, M. Pharm. (Pharmacology), Research Associate; Department of Pharmacology, Netaji Subhash Chandra Bose Subharti Medical College, Subhartipuram NH-58, Delhi Haridwar Bypass Road, Meerut, Uttar Pradesh, Pin- 250005, India, Tel+91-90I253794I,

Email fkpharmacy@gmail.com

Received: July 08, 2018 | Published: August 10, 2018

Keywords: type II diabetes mellitus, sprouted fenugreek seeds, fasting blood glucose, body mass index

\section{Introduction}

Many researchers have observed the effect of diabetes for hundreds of years. For many years, little data was known about this fatal illness that caused squandering without end of the body, excessive thirst, and frequent urine excretion. It wasn't until 1922 that the first patient was effectively treated with insulin. One of the major complications of diabetes is the increase level of glucose excrete in the urine (glucosuria). In Ayurveda, many years of old, reported how black ant and other insects such as flies were attracted roundly to the urine of diabetic patients. The Indian physicians Sushruta in about 400 B.C. proposed the sweet taste of urine from diabetic effective people, and for a many hundreds of years, the sweet taste of urine was a vital key to diagnose the disease of diabetes. Around 250 B.C., the name "diabetes" was first utilized. It is a Greek word that signifies "to siphon", reflecting how diabetes appeared to quickly drain fluid out of the affected person. The Greek doctor Aretaeus noticed that as effected people wasted away, they passed expanding measures of urine as if there seemed to be "liquefaction of flesh and bones into urine". The entire term "diabetes mellitus" was labeled in 1674 by Thomas Willis, personal doctor of King Charles II. Mellitus is Latin for sweet honey, which is the means by which Willis depicted the urine of diabetics ("as described as honey and sugar). ${ }^{1}$

Diabetes mellitus is a chronic disease of pancreatic origin which alters the insulin deficiency, causes hyperglycemia, glucose intolerance, and excess sugar in the blood and urine, weakness, low or defective insulin action or both. ${ }^{2}$ Pharmacologically diabetes caused by disturbance in the hormonal and cellular level in the body, which increase blood glucose levels to above $120 \mathrm{mg} / \mathrm{dl}$. The diet recommended for people with diabetes is used to help control and regulate blood sugar levels and body weight. ${ }^{3}$ The effects of diabetes mellitus include long-term damage, dysfunction and failure of various organs. Diabetes mellitus possess a list of symptoms which includes thirst heavily, polyuria, blurring of vision, and sometimes weight loss and uneven weight increase. When diabetic is in most critical forms, the patient develops ketoacidosis or a non-ketotic hyperosmolar state which leads to stupor, coma and may be death. Long term damage in diabetes include progressive development of specific complications of retinopathy can cause potential blindness and loss of vision, development of nephropathy which defects the nephron and cause renal failure, and/or foot ulcers due to neuropathy, a cause in the Charcot joints. Diabetes causes autonomic dysfunction, which include sexual problem and uneasiness. Peoples suffering from diabetes develops increased risk of disease such as peripheral, cardiovascular and cerebrovascular disease. ${ }^{4}$ Such macro-vascular and micro-vascular complications are start due to the defection in the endocrine systems of metabolic fuels in the body including the metabolism of carbohydrates, proteins and lipids coming from defective insulin secretions, insulin action, or both. ${ }^{5}$

Insulin is a hormone released from the pancreas by islets of $\beta$-cells. It manage the measure of glucose level in the blood by empowering cell glucose take-up by liver, skeletal muscle and adipocytes. ${ }^{6}$ Glucose is a sugar atom that gives essential vitality to the majority of the cells in the body. Glucose gets retained from the digestive tract and dispersed by the circulatory system to keep a consistent supply of glucose, by keeping up a constant glucose focus in the blood. To 
keep up a consistent blood glucose level, the pancreas assumes an essential part by emitting the hormones insulin and glucagon from beta and alpha cells. ${ }^{7}$ The pancreas plays a major role in the direction of macronutrient ingestion and consequently metabolism/energy homeostasis by discharging different stomach related enzymes and pancreatic hormones. Each number of hormones has particular functions towards maintaining the blood glucose. Glucagon enhances blood glucose levels, while insulin lowers blood glucose level Somatostatin inhibits both the amount of hormones. Although, these pancreatic hormones regulates blood glucose homeostasis. ${ }^{8}$ Impaired activity of insulin in the body can cause target tissues irregularities in protein, sugar and fat digestion. Subsequently, it enhanced amounts of glucose level in the blood and insufficient amount of glucose in the cells together possess the manifestations and difficulties of diabetes over the time.

\section{Diabetes with obesity}

There is a solid relationship connected between obesity (increased weight) and T2DM patients. If a person develops obesity and the duration of obesity is long the person has a major risk of developing T2DM and a higher rate to develop abdominal obesity..$^{10}$ Metaexamination of investigations of relationship of these two conditions indicated higher relative increase with BMI and also shows gain in waist hip ratio in both men and women. Studies found that not all the individual with type 2 diabetes are obese and all the obese or pre obese subjects are not diabetic. But majority of cases of diabetes are suffering from obesity. Noteworthy quantities of stout people have diabetes. These two symptoms can be manageable by changing in the lifestyle, avoid sedentary habits and reduce over consumption of fat/ energy. Both obese and T2DM patients, have a risk to develops insulin resistance and increase the level of triglycerides, decrease the amount of HDL-C. ${ }^{11}$ In common, obese patient have serious risk of congenital anomaly/birth defects and premature death by T2DM. ${ }^{12}$ It is noted that BMI and (especially visceral fat) adiposity are related with the advancement of T2DM. It was noted clearly that patient with T2DM with reduction of viable amount of weight; enhances the control on the level of glycaemia. ${ }^{13}$

\section{Diabetes and Metabolic syndrome}

Metabolic syndrome represents a group of related metabolic abnormalities which include central obesity, dyslipidemia, hypertension, hyperglycemia, with insulin insensitivity/resistance measured in individual as a causative factor. These cluster of metabolic defects present major risk factors for developing diabetes and cardiovascular disease. The individual with metabolic syndrome have higher tendency to develop T2DM compare to other diseases. ${ }^{14}$ Metabolic disorder is a dynamic condition that incorporates wide defects in the body with particular metabolic variations encompasses at different times. To determine the severity of the complication, WHO given the following criteria-The WHO definition of metabolic syndrome requires the presence of insulin resistance as identified by either of type II diabetes mellitus, impaired fasting glucose, or impaired glucose tolerance plus at least two of the following:

a. BMI $>30 \mathrm{~kg} / \mathrm{m}^{2}$ and $/$ or waist to hip ratio $>0.90$ in men or $>0.85$ in women.

b. Serum triglycerides $\geq 50 \mathrm{mg} / \mathrm{dl}(1.7 \mathrm{mmol} / 1)$ or HDL cholesterol $<35 \mathrm{mg} / \mathrm{dl}(0.9 \mathrm{mmol} / \mathrm{l})$ in $\mathrm{men}$ and $<39 \mathrm{mg} / \mathrm{dl}(1.0 \mathrm{mmol} / \mathrm{l})$ in women. c. Raised arterial blood pressure $\geq 140 / 90 \mathrm{~mm} \mathrm{Hg}$.

d. Rate of urinary albumin excretion $>20 \mu \mathrm{g} / \mathrm{min}$ or albumin to creatine ratio $\geq 30 \mathrm{mg} / \mathrm{g} .{ }^{15}$

\section{Nutraceuticals}

The term nutraceuticals was derived from 'Nutrition' and 'Pharmaceuticals' by Stephen Defelice, the founder and chairman of foundation for innovative medicine an American organization which encourages medical health. The most desirable definition of nutraceutical is to attain desirable therapeutic outcomes with reduced side effects. Nutraceuticals are utilized as substance or part of nourishment which will give restorative or medical advantages including prevention and management of disease/disorder. Home grown (Herbal) nutraceuticals are effective products in keeping up wellbeing, nutritionally induced acute and chronic diseases promoting in improving optimal health, live long and improve quality of life. Nutritional treatment is a healing framework that utilizes dietary therapeutics. This treatment depends on the conviction that food not only the source of supplements and vitality as well as give medicinal advantages. ${ }^{16}$

\section{Fenugreek (Trigonella foenum-graecum)}

The scientific name of fenugreek is Trigonella foenum-graecum an annual plant under the family of Fabaceae. Fenugreek is a medicinal plant that is being used as therapy in diabetes. Medicinal plants are used by $80 \%$ of the world population as the only available medicines especially in developing countries. Fenugreek plant has lipid lowering and sugar decreasing in diabetic and non diabetic peoples and has antioxidant and antibacterial activity. Fenugreek plant decrease body fats and effective on obesity. ${ }^{17}$

\section{Phytochemistry of Trigonella foenum-graecum Sprouted Seed}

Phytochemical comes from the Greek word "phyto" for plant. It refers to every naturally occurring chemical presents in plants. In plants, phytochemicals act as a natural defense system for host plants and provide color, aroma and flavor. The most important action of these chemicals possess on human beings is to increase the level of antioxidant in the body that react with the free oxygen molecules. The chemical constituents of sprouted fenugreek seeds contains various components which are responsible for his activity like water, flavonoids, crude fiber, crude fat, starch, minerals, and crude protein (Figure 1). ${ }^{18}$

\section{Nutritional content}

The effect of soaking (sprouting) of fenugreek seeds make it more nutritional and raise the number of its nutritional and dietary contents compares to dried fenugreek seeds. The sprouted seeds of fenugreek have high protein content $(32 \%)$, lysins $(5.7 \mathrm{~g} / 16 \mathrm{~g}$ of nitrogen), soluble $(20 \%)$ and insoluble $(28 \%)$ dietary fibre, L-tryptophan and rich in calcium, iron and beta-carotene. The three main chemical constituent of fenugreek seed with desired potential medicinal uses; these are, steroidal sapogenins, galactomannans and isoleucine. These constituents have set fenugreek among the most generally perceived "nutraceutical" or health food items. ${ }^{19}$

The sprouted (germinated) seeds of the fenugreek contain many of the effective compounds with their medicinal, therapeutic and pharmaceutical applications. The chemical and medicinal components 
of fenugreek seed include vitamin $\mathrm{A}$, vitamin $\mathrm{B} 1$, vitamin $\mathrm{C} \& \mathrm{E}$, phosphates, flavonoids, saponins, trigonelline, alkaloids, flavonoids, steroids, saponins, polyphenolic substances, carbohydrates, flavonoids (apigenin, luteolin, orientin, quercetin, vitexin and isovitexin) free amino acids, such as 4-hydroxyisoleucine, arginine, histidine and lysine, saponins, glycosides etc. ${ }^{20}$

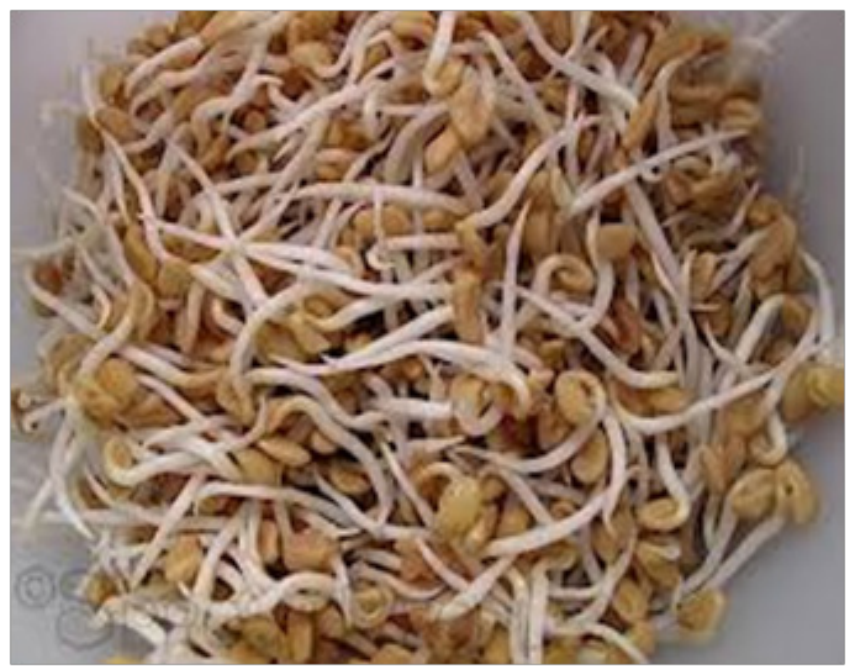

Figure I Sprouted fenugreek seeds.

\section{Taxonomic classification ${ }^{21}$}

Table 1

Table I Taxonomic classification of fenugreek plant

\begin{tabular}{ll}
\hline Kingdom & Plantae \\
\hline Subkingdom & Tracheobionta \\
Super division & Spermatophyta \\
Division & Magnoliophyta \\
Class & Magnoliopsida \\
Subclass & Rosidae \\
Order & Fabales \\
Family & Fabaceae \\
Genus & Trigonella \\
Species & T. Foenum-graecum \\
\hline
\end{tabular}

\section{Materials and methods}

\section{Study area}

Design of the study was prospective and carried out on 100 already diagnosed patients who were suffering from diabetes mellitus, obesity and metabolic syndrome. Patients met with the inclusion criteria enrolled for the study. The study was carried out under the supervision of Maharishi Aurobindo Subharti College \& Hospital of Naturopathy \& Yogic Sciences, Swami Vivekanand Subharti University, Meerut (U.P). The age of the patients was $18-70$ years. All the patients were duly informed about the research work, possible effects and known side effects of sprouted fenugreek seeds. The patient was enrolled in the study with their own interest, and a written informed consent was taken from everyone. The duration of this study was 6 months (24 weeks). An approval of Institutional ethics committee was obtained before the start of the study.

\section{Study design and period}

Experimental study using quantitative methods was conducted to study the effect of sprouted fenugreek seeds on type II diabetic, obese and metabolic syndrome patients. The study was conducted during the period of November 13, 2017 to May 28, 2018.

\section{Source Population}

All the diabetic and obese patients coming to the Maharishi Aurobindo Subharti College \& Hospital of Naturopathy \& Yogic Sciences, Meerut.

\section{Study Population}

All diagnosed type II diabetic and obese patients at the Maharishi Aurobindo Subharti college \& Hospital of Naturopathy \& Yogic Sciences who are willing to participate in the study and able to give informed consent.

\section{Experimental design}

Design: Prospective add-on study.

Patients were divided into two groups:

Group 1 (Treatment group): Patients were given the standard treatment protocol, diet, exercise and $25 \mathrm{gm}$ sprouted fenugreek seeds for 45 days.

Group 2 (Control Group): Patients were on anti-diabetic drugs, except sprouted fenugreek seeds.

Parts of plant used: Sprouted fenugreek (Trigonella foenumgraecum) seeds

Dose used: $25 \mathrm{gm}$ of sprouted fenugreek seed

\section{Eligibility criteria}

\section{Inclusion criteria}

a) Subject diagnosed with type $2 \mathrm{DM}$, obesity and metabolic syndrome.

b) Age $18-70$ years

c) Patients on insulin or any oral hypoglycemic therapy.

d) $\mathrm{HbA}_{1} \mathrm{C}$ more than $8 \%$

e) Presence of dyslipidemia (deranged lipid profiles)

f) Glycemia and dyslipidemia controlled or not controlled with drugs.

\section{Exclusion Criteria}

a) Patients who are not willing to participate in the study and unable to give informed consent.

b) Patient having liver diseases, pulmonary tuberculosis and other serious disease.

c) Patients with ischemic heart disease.

d) Patient with any diabetic complications such as neuropathy, 
nephropathy, or retinopathy.

e) Pregnant women.

f) Human immunodeficiency virus (HIV) infection.

\section{Sampling technique}

Patients who satisfied the eligibility criteria were randomized to treatment and control groups. The treatment group received $25 \mathrm{gm}$ of sprouted fenugreek seeds twice daily along with exercise and diet modification for 45 days, while controls group did not received any dose of fenugreek sprouts.

\section{Response rate}

A total of 100 patients were enrolled for the study, 90 completed the study, 40 in treatment group and 50 in the control group, but some dropped out of the study: 6 patients in first two weeks, 4 patients in second two weeks for reasons unrelated to the use of sprouted fenugreek seeds and for its taste.

\section{Preparation of diet chart}

Table 2

Table 2 Diet chart of diabetic and obese patient

\begin{tabular}{|c|c|}
\hline Food item & Amount \\
\hline \multicolumn{2}{|l|}{ Early morning } \\
\hline Tepid water & $2-3$ glass \\
\hline Sprouted fenugreek seeds & $\begin{array}{l}3 \text { table spoon } \\
\text { (aprox. } 25 \mathrm{mg} \text { ) }\end{array}$ \\
\hline Lemon tea & I cup \\
\hline Fiber biscuits OR & 2 \\
\hline Cucumber shake or Vegetable shake & I medium bowl \\
\hline \multicolumn{2}{|l|}{ Breakfast } \\
\hline $\begin{array}{l}\text { Stuffed green methi/palak/lauki paratha } \\
\text { or roti }\end{array}$ & 2 small \\
\hline Curd & I cup (50 gm) \\
\hline \multicolumn{2}{|l|}{ OR } \\
\hline Vegetable poha/upama/oats/daliya & I soup bowl \\
\hline \multicolumn{2}{|l|}{ Mid morning } \\
\hline Orange/apple/guava & 1 \\
\hline Blackberry (Jamun) & I bowl \\
\hline \multicolumn{2}{|l|}{ Lunch } \\
\hline Salad (I0 mins before lunch) & I medium bowl \\
\hline Capsicum + gobhi veg & I medium bowl \\
\hline \multicolumn{2}{|l|}{ OR } \\
\hline Bitter- Gourd with onion veg & I medium bowl \\
\hline Dal & I soup bowl \\
\hline Phulka (no ghee) & 2 \\
\hline \multicolumn{2}{|l|}{ Evening } \\
\hline $\begin{array}{l}\text { Green tea/Milk (without sugar)/herbal } \\
\text { tea/lemon tea }\end{array}$ & I cup \\
\hline
\end{tabular}

\begin{tabular}{ll} 
Table Continued & Amount \\
\hline Food item & I cup \\
\hline Roasted chana + puffed rice OR corn & \\
Dinner & I medium bowl \\
Salad I0 mins before dinner) & 2 \\
Phulka ( No ghee) & I cup \\
Lauki veg & I cup \\
Curd & \\
Late night & I glass \\
Skim milk (without sugar) &
\end{tabular}

\section{Data collection procedure}

Preliminary data was collected at the baseline (Day1) in a standardized format which included the information about the sociodemographic profile, behavioral and clinical characteristics related to the disease.

\section{Clinical measurements}

\section{Measurement of fasting blood glucose and PP blood sugar}

Measurements were made at baseline (before treatment) and at the end of study. Fasting blood glucose level and postprandial blood glucose was measured on day1, day 15 , day 30 and day 45 . Blood was measured by Dr. Morepen GlucoOne BG-03 blood glucose monitoring device at 8:30 am from the tip of middle finger. The middle finger pricked by a needle device for collection of a drop of blood. The first drop of the blood was removed (presence of plasma and proteins) by cotton and second drop was transferred onto the test strip. The digital meter of the device was made ready for analyzing the blood glucose by counting 1 to 5 seconds. Reading of blood glucose was measured and recorded in the table. The measured valued of FBS and PPBS reading were compared with baseline and control group.

\section{Measurement of body mass index (BMI)}

Body mass index was measured as weight in kilograms divided by the square of their height in meter. Weight was measured while patients were wearing light clothing without shoes by using the weighing scale. Reading was taken to the nearest 0.5 kilograms. Height measurement was taken using portable tape meter without shoes and recorded to the nearest 0.5 centimeters. A person's weight status is categorized according to the level of BMI (as per W.H.O) as shown in the table below (Table 3).

Table 3 BMI range as per World Health Organization (WHO)

\begin{tabular}{ll}
\hline Weight status & BMI $\left(\mathbf{k g} / \mathbf{m}^{2}\right)$ \\
\hline Underweight & $\leq 18.5$ \\
Normal & $18.5-24.9$ \\
Overweight or pre-obese & $25-29.5$ \\
Obese (Class I) & $30-34.9$ \\
Obese (Class II) & $35-39.9$ \\
Obese (Class III) & $>40$ \\
\hline
\end{tabular}

\section{Blood pressure (BP) and heart rate/or pulse rate (PR)}

Blood pressure is the force of blood pushing against blood vessel walls. It is measured in millimeters of mercury $(\mathrm{mm} \mathrm{Hg})$. While heart 
rate (also called pulse rate) is the number of times your heart beats every minute. It is denoted by beat per minute (BPM). Heart rate varies to one to other person; a normal range of BP in adults is 60 to $100 \mathrm{bpm}$, according to the American Heart Association.

\section{Ethical consideration}

It was only an observational study. The diagnostic and treatment modalities given to patients was be recorded. Privacy of identity was maintained. The thesis proposal was reviewed and approved by the Institutional Ethical Committee (IEC) (Ref No: SMC/IEC/2017/194) of the Department of Pharmacology, Subhash Chandra Boss Subharti Medical College, Swami Vivekanand Subharti University, Meerut. The research started after ethical clearance was obtained.

\section{Authentication of plant and seed}

Plant of Trigonella foenum-graecum and its seed was authenticated by Department of Botany, Choudhary Charan Singh University, Meerut. The reference (Bot./625/17.04.18) of crude drug and its seeds sample authentication was obtained.

\section{Results and discussion}

\section{Baseline blood glucose level (FBS \& PPBS), BMI, PR and $B P$.}

As can be seen in Table 4 at the beginning of the study both the Treatment and control group had abnormal blood glucose levels (FBS \& PPBS), abnormal BMI, PR and Blood Pressure.

Table 4 FBS, PPBS, Weight, BMI, PR and BP measured on day I

\begin{tabular}{|c|c|c|c|}
\hline \multicolumn{4}{|l|}{ Parameters } \\
\hline \multicolumn{2}{|c|}{ Baseline value } & Treatment group & Control group \\
\hline \multicolumn{2}{|l|}{ FBS (mg/dl) } & $176.5 \pm 94.2$ & $|29.3 \pm 4| .5$ \\
\hline \multicolumn{2}{|l|}{ PPBS (mg/dl) } & $273 \pm 131.6$ & $238.7 \pm 101.0$ \\
\hline \multicolumn{2}{|l|}{ Weight (kg) } & $69.5 \pm 12.3$ & $68.5 \pm 5.9$ \\
\hline \multicolumn{2}{|l|}{ BMI $\left(\mathrm{kg} / \mathrm{m}^{2}\right)$} & $31.2 \pm 5.2$ & $28.4 \pm 2.7$ \\
\hline \multicolumn{2}{|l|}{ PR (bpm) } & $79.7 \pm 5.1$ & $79.4 \pm 8.2$ \\
\hline \multirow{2}{*}{$\mathrm{BP}(\mathrm{mm} \mathrm{Hg})$} & Systolic & $124.8 \pm 8.3$ & $121.0 \pm 6.8$ \\
\hline & Diastolic & $82.2 \pm 7.8$ & $79.0 \pm 5.1$ \\
\hline
\end{tabular}

Data are expressed as mean \pm SD

\section{The effect of sprouted fenugreek seeds on FBS level}

The treatment group was received sprouted fenugreek seeds for 45 consecutive day's had statistically significant decreased FBS level compared with baseline FBS level 17.\% (176.5 \pm 94.2 vs. $146 \pm 46.3$ ), $23.4 \%(176.5 \pm 94.2$ vs. $135.1 \pm 33.9)$ and $36.7 \%$ (176.5 \pm 94.2 vs. $111.7 \pm 25.6(\mathrm{P}<0.05))$ on day 15,30 and day 45 respectively (Figure 2).

\section{The effect of sprouted fenugreek seeds on PPBS level}

The treatment group was received sprouted fenugreek seeds for 15 consecutive days had statistically significant decreased PPBS level compared with baseline PPBS level 14\% (273.2 \pm 131.5 vs. $234.7 \pm 91.2$ $(\mathrm{P}=0.43)), 30.7 \%(273.2 \pm 131.5$ vs. $189.3 \pm 64.3(\mathrm{P}=0.07))$ and $34 \%$ $(273.2 \pm 131.5$ vs. $180.3 \pm 54.7(\mathrm{P}<0.05))$ on day 15,30 and day 45 respectively. However, the control group which had not received sprouted fenugreek seeds shows no significant change of PPBS level $238.7 \pm 101$ vs. $225.3 \pm 82.1$ ( $\mathrm{P}=0.72), 238.7 \pm 101$ vs. $206.3 \pm 75$ $(\mathrm{P}=0.38)$ and $238.7 \pm 101$ vs. $195.9 \pm 82.7(\mathrm{P}=0.26)$ compared with their baseline PPBS level on day 15, 30 and day 45 respectively (Figure 3).

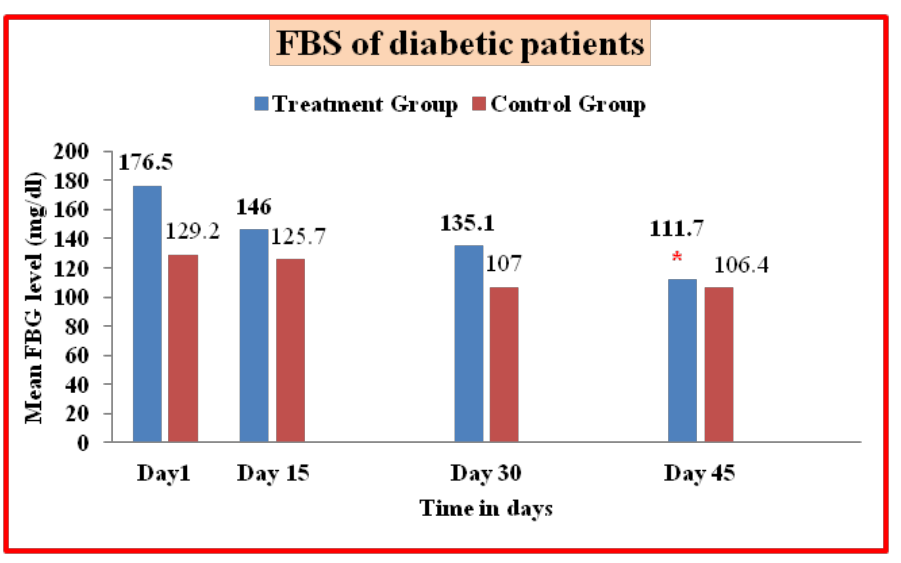

Figure 2 FBS level of the treatment and control group on day I, I5, 30 and day 45.

$$
\begin{aligned}
& \checkmark \text { The result expressed as mean } \pm \text { SD. } \\
& \checkmark \text { *Indicates significant differences }(\mathrm{P} \leq 0.05) \text {, treatment vs. control group }
\end{aligned}
$$
on day 45.

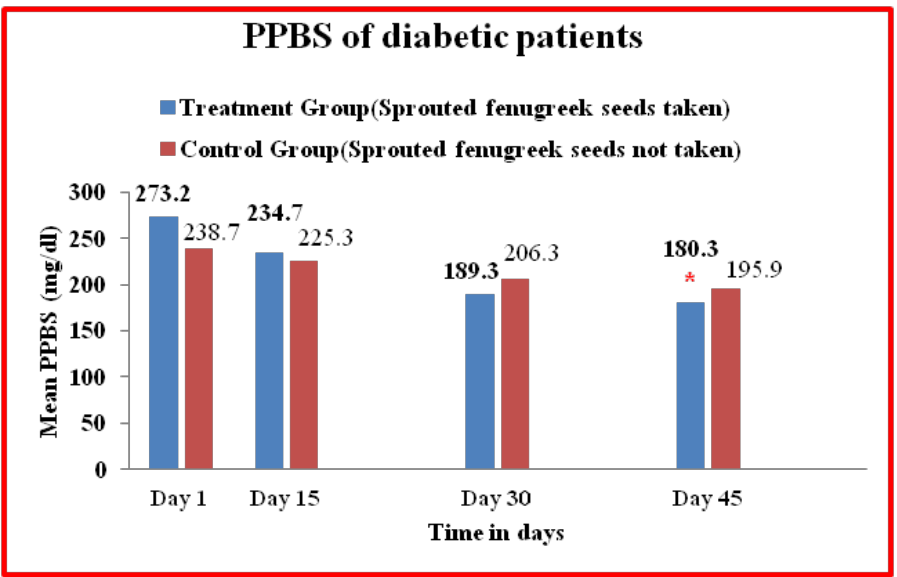

Figure 3 PPBS level of the treatment and control group on day I, day I5, day 30 and day 45 .

$$
\begin{aligned}
& \checkmark \text { The results are expressed as mean } \pm \text { SD. } \\
& \checkmark \text { *Indicates significant differences }(P \leq 0.05) \text {, treatment vs. control group } \\
& \text { on day } 45 \text {. }
\end{aligned}
$$

\section{The effect of sprouted fenugreek seeds on weight of diabetic patients}

Figure 4 shows the weight of diabetic patient in treatment group on day 1 , day 15 , day 30 and day 45 following administration of $25 \mathrm{gm}$ of sprouted fenugreek seeds in twice a day. The data shows that weight of the treatment group had significantly decreased as compared with baseline weight and with control group throughout the study period. The treatment group was received sprouted fenugreek seeds for 15 consecutive days had reduced weight of diabetic patients compared with baseline weight $5 \%(69.5 \pm 12.3$ vs. $66 \pm 12), 7.4 \%(69.5 \pm 12.3$ vs. $64.3 \pm 11.1)$ and $14.3 \%(69.5 \pm 12.3$ vs. $59.5 \pm 10(\mathrm{P}<0.05))$ on day 15 , 30 and day 45 respectively (Figure 4 ). 


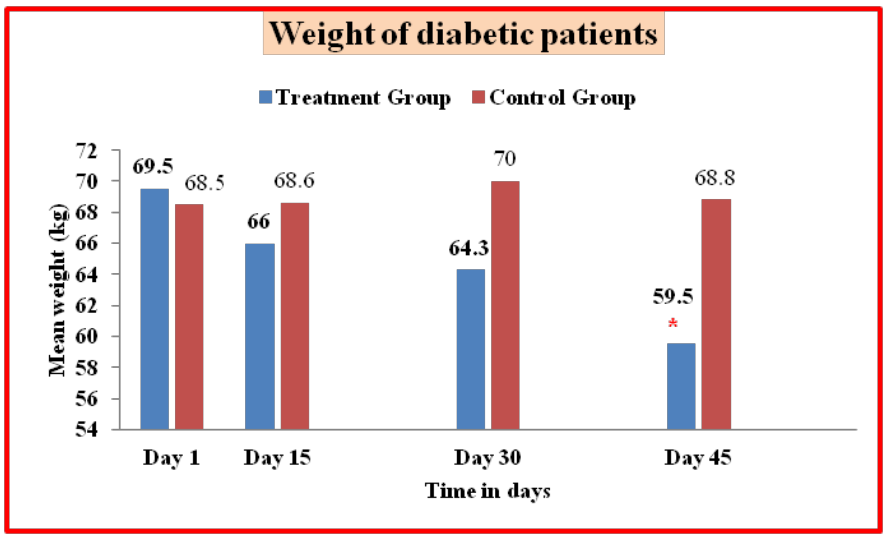

Figure 4 Weight of treatment and control group on day I, day 15, day 30 and day 45.

$$
\begin{aligned}
& \checkmark \text { The results are expressed as mean } \pm \text { SD. } \\
& \checkmark \text { *Indicates significant differences }(P \leq 0.05) \text {, treatment vs. control group } \\
& \text { on day } 45 \text {. }
\end{aligned}
$$

\section{The effect of sprouted fenugreek seeds on BMI}

Figure 5 demonstrated the BMI of the treatment group on day 1, day 15 , day 30 and day 45 following administration of $25 \mathrm{gm}$ of sprouted fenugreek seeds in twice a day. The data shows that BMI of the treatment group had significantly lowered as compared with baseline BMI and with control group throughout the study period. The treatment group was received sprouted fenugreek seeds for 45 consecutive days had reduced BMI compared with baseline BMI $8.2 \%(26.7 \pm 7.5$ vs. $24.5 \pm 6.5), 11.2 \%$ (26.7 \pm 7.5 vs. $23.7 \pm 4.9)$ and $20.5 \%(26.7 \pm 7.5$ vs. $21.2 \pm 4.3(\mathrm{P} \leq 0.05))$ on day 15,30 and day 45 respectively. The treatment group showed statistically significant reduction in BMI range when compared with the baseline BMI range of diabetic patients. Day 1 was the baseline of the treatment and control group (Figure 5).

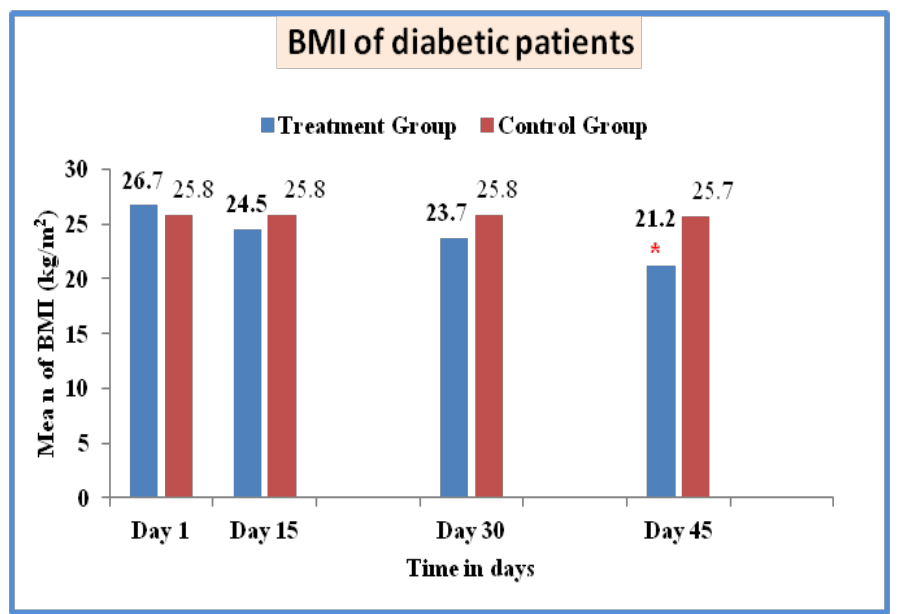

Figure $5 \mathrm{BMI}$ of the treatment and control group on day I, day 15, day 30 and day 45 .

\footnotetext{
$\checkmark$ The results are expressed as mean \pm SD.

$\checkmark$ *Indicates significant differences ( $\mathrm{P} \leq 0.05)$, treatment vs. control group on day 45 .
}

\section{The effect of sprouted fenugreek seeds on pulse rate (PR)}

The treatment group was received sprouted fenugreek seeds for 45 consecutive days had statistically decreased PR compared with baseline PR $6.1 \%$ ( $92.1 \pm 7$ vs. $86.4 \pm 6.5), 8.2 \%$ ( $92.1 \pm 7$ vs. $84.5 \pm 5.8)$ and $10.5 \%(92.1 \pm 7$ vs. $82.4 \pm 5.4(\mathrm{P}<0.001))$ on day 15,30 and day 45 respectively (Figure 6).

\section{The effect of sprouted fenugreek seeds on blood pressure (BP)}

The treatment group was received seeds of fenugreek (sprouted) for 45 consecutive days had decreased both systolic and diastolic BP compared with baseline $2.1 \%$ (Sys.) ( $132 \pm 11$ vs. $129.1 \pm 8.5), 0.2 \%$ (Dia.) $(85.8 \pm 5$ vs. $85.6 \pm 4.5), 4 \%$ (Sys.) (132 \pm 11 vs. $126.6 \pm 6.3)$, $2.7 \%$ (Dia.), $2.7 \%$ ( $85.8 \pm 5$ vs. $83.4 \pm 3.2$ ), $5.3 \%$ (Sys.) (132 \pm 11 vs.124.4 \pm 5.9$), 3.6 \%$ (Dia.) $(85.8 \pm 5$ vs. $81 \pm 3.2)$ on day 15,30 and day 45 respectively (Figure 7).

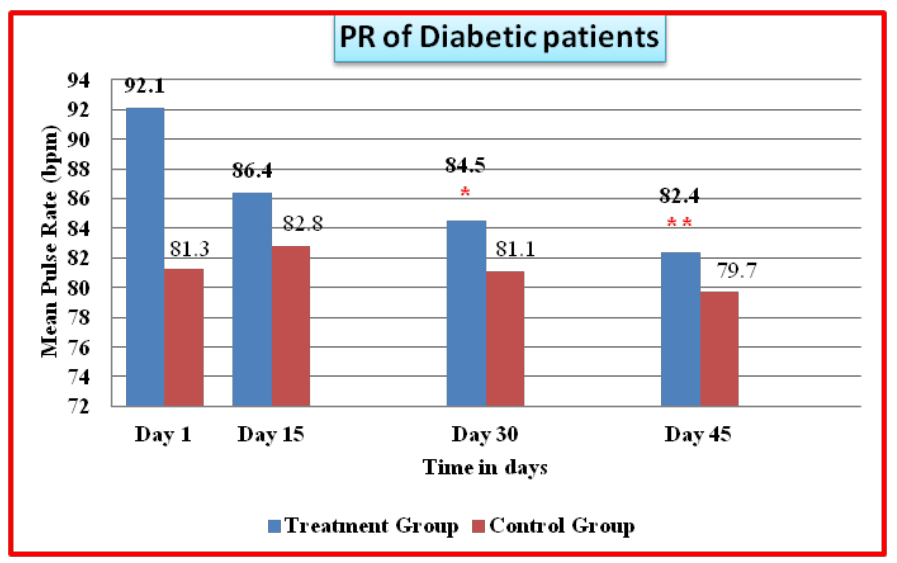

Figure 6 PR of the treatment and control group on day I, day 15, day 30 and day 45 .

$\checkmark$ The results are expressed as mean \pm SD.

$\checkmark$ *Indicates significant differences ( $P \leq 0.05)$, treatment vs. control group on day 30 .

$\checkmark$ **Indicates highly significant differences $(\mathrm{P} \leq 0.00 \mathrm{I})$, treatment vs. control group on day 45 .

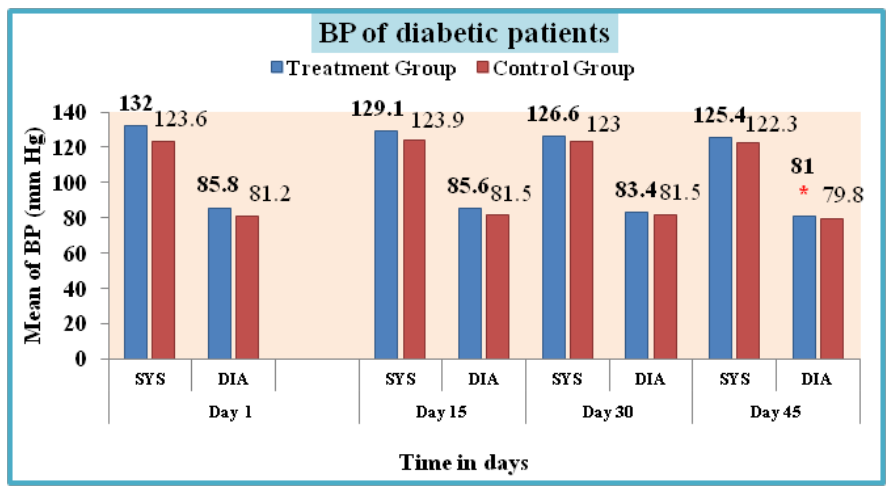

Figure 7 BP of the treatment and control group on day I, day 15, day 30 and day 45 .

$\checkmark$ The results are expressed as mean \pm SD.

$\checkmark$ *Indicates significant differences $(P \leq 0.05)$, treatment vs. control group on day 45. 


\section{Discussion}

Diabetes mellitus is a metabolic disorder characterized by chronic hyperglycemia resulting from absolute or relative lack of insulin secretion or insulin resistance by peripheral tissues. Diabetes has high prevalence in worldwide and it is a major cause of morbidity and mortality in every year. Diabetes is non curable but controllable disease and it is possible due to changing lifestyle, decreases physical activities, smoking and eating too much of salt and fast foods leading to metabolic defects in the body; which may cause diabetes and obesity.

Management of type II DM is difficult with the synthetic drugs as they cause many side-effects and have some limitations. Thus, as an alternative, there is an immense interest in medicinal plants for management of type II DM with indigenous, inexpensive, foodbased treatment. Scientists have started looking into the herbal extracts to observe their effective and protective role in the diabetic animal and humans models. One of such herbal plants is fenugreek having scientific name of Trigonella foenum-graecum. The present work demonstrates a significant role of sprouted fenugreek seeds in reducing blood glucose levels, body mass index, pulse rate, blood pressure and reduction of weight in type II diabetic patients or in metabolic disorder.

Another procedure to control the metabolic defects is to changing the lifestyle and modification in the routine life. Enhancing physical activity, exercise and diet modification had shows lower the symptoms of diabetes, obesity and metabolic disorder. Addition of sprouted fenugreek in the diet for two times and doing exercise and/ or Yoga helps to synergistic reduced the level of blood sugar in the body and metabolic syndrome. In the current study, administration of $25 \mathrm{mg}$ sprouted fenugreek seeds in type II diabetic patients produced significant decreased in fasting blood sugar level $(\mathrm{p}<0.05)$ and post prandial blood sugar level $(\mathrm{p}<0.05)$ compared with the pretreatment blood glucose level Figure 2. It interferes with stimulation of insulin from $\beta$ cells and improved insulin sensitivity towards the binding site. The generation of IP-3 pathway was stimulated and decreases the formation of new glucose molecule by the liver by inhibiting glyconeogenesis. However, the control group do not shows any significant decrease in blood glucose level but effect of taking medicine reduce level of blood sugar. Furthermore, sprouts of fenugreek seeds with generation of fibers may interfere with the absorption of active ingredients of sprouted seeds of fenugreek in the stomach and increased amount of protein and crude fibers.

Our result suggests that sprouted fenugreek seed has a potential anti hyperglycemic effect although the mechanism of action is not well defined. But several hypotheses have been put forward in this respect. In recent study the anti hyperglycemic effect of sprouted fenugreek seed has been hypothesized to be due to the amino acid 4 hydroxyisoleucine found in the fenugreek seed that acts by stimulating the secretion of insulin, increase insulin sensitivity and glucose uptake in peripheral tissues. The remarkable reduction of both type of blood glucose level might be due to the effect of sprouted fenugreek seeds in stimulating insulin synthesis by stimulation of pancreatic $\beta$ cell, secretion and action, restoration of insulin and have "insulin like" activity in sprouts of fenugreek. By shows this action by maintained glucose homeostasis. It was also suggested that the antihyperglycemic effects of sprouted fenugreek seeds could be caused by high level of soluble and insoluble fiber which interfere with carbohydrate absorption, decreased gastric emptying time and thus delaying the absorption of glucose from the small intestine. Further, it increased peripheral uptake of glucose also regenerate the $\beta$-cells and enhanced the sensitivity of insulin receptor.

In addition to its anti-hyperglycemic effect, sprouted fenugreek seeds reduced the weight of type II diabetic with obese and non obese patients. Weight is one of the common characteristics of type II DM. In this study weight was significantly reduced in treatment group by administration of $25 \mathrm{gm}$ sprouted fenugreek seeds for 45 consecutive days. Significantly reduced weight $(\mathrm{p}<0.05)$ compared with control groups (Figure 4). The reductions of weight by fenugreek sprouts was due to crude fiber, saponins content in fenugreek seed and the effect of estrogenic constituent. Sprouted fenugreek seeds may delay the absorption of glucose and fatty acids, thus providing less substrate for synthesis of triglycerides, LDL and VLDL. The current study demonstrated the reduction of both men and women body mass index after taken the sprouted seeds of fenugreek for 45 days. The reduction of BMI was statistically significant $\mathrm{P}=<0.05$ had shown in Figure 5 . The study demonstrated the reduction in BMI due to its proteins and fibers and also enhanced the gastric empting time. Once the BMI was reduced the abdominal fat was also reduced. It was noted that reduction of weight reduces BMI and decrease in the level of BMI reduces waist hip ratio. These parameters are connected with each others; reduction of one parameter can alter the other. Likewise, sprouted fenugreek seeds were effectively decreased Pulse Rate (PR) when treated the hypertensive patient for 45 days. Pulse Rate was decreased which was statistically significantly $(\mathrm{p}<0.05)$ has been shows in Figure 6 .

On the other hand the reduction of diastolic blood pressure shown in Figure 7 with statistically significant value $(\mathrm{P}=<0.05)$. The systolic blood pressure shows reduction in their value but was not statistically significant $(\mathrm{P}>0.05)$. It was shown that the hypertensive patient taking sprouted fenugreek has been reduce the blood pressure but systolic BP was not significant it was may be due to not taking any kind of antihypertensive drug. However, in some finding there was no any reduction of blood pressure by fenugreek or its seeds. But patient taking fenugreek sprouts reduces the systolic as well as diastolic BP. The present study showed that the Trigonella foenum-graecum sprouted seeds taken by metabolic patients produced a significant reduction in FBS, PPBS, weight, BMI, BP and PR pronounced improvement of diabetic patients. The patients reduced these metabolic defects due to given the treatment modalities (sprouted fenugreek seeds, exercise and diet) compared to control and treated group.

\section{Conclusion}

The reference use of fenugreek in obesity, metabolic syndrome and diabetes mellitus are available in indigenous system literature i.e. AYUSH literature but there are little data being contemporary in modern parameters of outcome. Generating data in modern system of medicine, methods using indigenous medicine are the need of the time to critically evaluate their place and in present era. Since, it involves multiple disciplines of medicine, i.e. pharmacognosy, pharmacy and naturopathy. Thus, the present study was done involving pharmacy, naturopathy/AYUSH and allopathic know how to find place of sprouted fenugreek seeds and lifestyle modifications as per naturopathy principles using allopathic/modern medicine parameters. The present study showed that the Trigonella foenumgraecum sprouted seeds taken by type II diabetic mellitus patients produced a significant reduction in fasting blood sugar level, post prandial blood sugar level and also reduced weight of the diabetic as well as obese patients. Sprouted fenugreek seeds lower the BMI 
range with contrast to reduction in weight. We know blood pressure is the silent killer of diabetic as well as non diabetic obese patients. High mortality and morbidity are seen because of high blood pressure. So, we need a home remedy to find out the prevention and management of high blood pressure. The medicinal value of sprouted fenugreek seeds was showed to reduce the systolic and diastolic blood pressure in diabetic complications and non diabetic obese and/or metabolic disorder patients. The additional benefits of taking sprouted fenugreek seeds was to reduces the pulse rate in hypertensive diabetic as well as obese hypertensive patient to a significant level of reduction. This investigation reveals that sprouted seeds of Trigonella foenum-graecum are potent natural food source that has a capacity to control the blood glucose level and reduces metabolic parameters of the patient. Therefore, sprouted fenugreek seeds may provide new alternatives for the clinical management of type II diabetes mellitus, obesity and metabolic syndrome.

\section{Acknowledgements}

None.

\section{Conflict of interest}

The author declares that there is no conflict of interest.

\section{References}

1. Dean L, McEntyre J. The Genetic Landscape of Diabetes. United States: National Center for Biotechnology Information; 2004

2. Rahman MM. Hypoglycemic and hypolipidemic effect of fenugreek in different forms on experimental rats. World Applied Sciences Journal. 2014;29(7):835-841.

3. Richard EJ, Augustine AO, Any CO, et al. Serum urea, uric acid and creatinine levels in diabetic mellitus patients attending jos university teaching hospital, north central nigeria. International Journal of Biosciences. 2017;11(4):68-72.

4. Aschner P, Assal JP. Definition, Diagnosis and Classification of Diabetes Mellitus and its Complications. Geneva: World Health Organization; 1999. 2 p.

5. Piero MN, Nzaro GM, Njagi JM, et al. Diabetes mellitus-a devastating metabolic disorder. Asian Journal of Biomedical and Pharmaceutical Sciences. 2014;4(40):1-7.

6. Begashaw GB, Yohannes YB, Moges WK, et al. Survival analysis of type II diabetes mellitus patients: a case study at menellik II referral hospital addis ababa, ethiopia. American Journal of Theoretical and Applied Statistics. 2017;6(6):311-324.
7. Yibru E, Menon M, Belayneh Y. et al. The effect of coriandrum sativum seed extract on hyperglycemia, lipid profile and renal function in streptozotocin induced type-2 diabetic swiss albino mice. International Journal of Health Sciences and Research. 2015;5(7):166-177.

8. Roder PV, B Wu, Liu Y, et al. Pancreatic regulation of glucose homeostasis. Exp Mol Med. 2016;48:e219.

9. https://www.scribd.com/document/258185413/Sretenka-IvanovicSeminar-Paper (25/05/2018).

10. Reis JP, Hankinson AL, Loria CM, et al. Duration of abdominal obesity beginning in young adulthood and incident diabetes through middle age: the cardia study. Diabetes Care. 2013;36(5):1241-1247.

11. Yaturu S. Obesity and type 2 diabetes. Journal of Diabetes Mellitus. 2011;1(4):79-95.

12. Garrow JS. Obesity and Related Diseases. London: Churchill Livingstone; 1988. $16 \mathrm{p}$.

13. Aftab SA, Reddy N, Smith E, et al. Obesity and Type 2 Diabetes Mellitus. Internal Medicine. 2014;2(6):1-6.

14. Srikanthan K, Feyh A, Visweshwar H, et al. Systematic review of metabolic syndrome biomarkers: a panel for early detection, management, and risk stratification in the west virginian population. Int $J$ Med Sci. 2016;13(1):25-38.

15. Jaber LA, Brown MB, Hammad A, et al. The prevalence of the metabolic syndrome among arab americans. Diabetes Care. 2004;27(1):234-238.

16. Pandey M, Verma RK, Shubhini AS, et al. Nutraceuticals: new era of medicine and health. Asian Journal of Pharmaceutical and Clinical Research. 2010;3(1):47-50.

17. Akbari M, Rasouli H, Bahdor T. Physiological and pharmaceutical effect of fenugreek: a review. Journal of Pharmacy. 2012;2(4):49-53.

18. Biba VS, Lakshmi S, Dhanya GS, et al. Phytochemical analysis of annona squamosa seed extracts. International Research Journal of Pharmaceutical and Applied Sciences. 2013;3,(4):29-31.

19. Agrawal RS, Shirale DO, Syed HM. Physico-chemical properties of fenugreek (Trigonella foenum-graceum L.) seeds. International Journal of Latest Technology in Engineering, Management \& Applied Science. 2015;4(10):68-70.

20. Kor NM, Didarshetaban MB, Pour HRS. Fenugreek (trigonella foenumgraecum L.) as a valuable medicinal plant. International Journal of Advanced Biological and Biomedical Research. 2013;1(8):922-931.

21. Ghosh B, Chandra I, Chatterjee S. Fenugreek (Trigonella foenumgraecum L.) and its necessity. Fire Journal of Engineering and Technology. 2015;1(1):60-67. 